\title{
INVISIBLE WOMEN BY CAROLINE CRIADO-PEREZ
}

\author{
He Rourou, Volume 1, Issue 1, 96-98, 2021 \\ BEX TAYLOR
}

Caroline Criado Perez, Invisible Women: Exposing Data Bias in a World Designed for Men, Abrams Press: New York, 2019. 432 pp. ISBN: 9781784741723

Invisible Women by Caroline Criado-Perez is a book about the gender data gap. An issue that is intrinsically weaved through our lives in countless ways. A silence, an absence of data, of perspective, of stories from $51 \%$ of the world's population. It's a book about why this gap exists, the consequences and how to reduce the gap.

The author, Criado-Perez is a writer, broadcaster, and feminist activist. She was named Liberty Human Rights Campaigner of the Year and OBE by the Queen. Invisible Women is her first book, published in 2019 and what a debut. She's been described as one of the most vocal and tenacious campaigners of her generation.

I know that gender equality is not a new topic, it has and always will be incredibly important. But with the rise in algorithms and artificial intelligence, Criado-Perez states it's never been more critical to act now. The gap will only grow, and the consequences, as Caroline Criado Perez details in her book, can be deadly. I had to pick my jaw off the ground at the end of each chapter, and at times wanted to throw it against the wall - not for dislike - but in total shock and frustration at how these situations existed and even as a woman, I felt like I didn't know enough. However, the purpose of the book is not to point fingers. She isn't interested in blaming anyone, or finding out if people were 'secretly sexist'. It's designed to inform, to educate, to show the patterns, and therefore illustrate that it is not just 'one big coincidence'.

"One of the most important things to say about the gender data gap is that it is not generally malicious, or even deliberate. Quite the opposite. It is simply the product of a way of thinking that has been around for millenia and is therefore a kind of not thinking. A double not thinking, even: men go without saying, and women don't get said at all. Because when we say human, on the whole, we mean man."

Criado-Perez's book can either be read from start to finish or a certain chapter can be selected for examples in that field or that industry - for example public transport, using the bathroom, or going to the doctor.

Criado-Perez's reason for writing this book was the urgency of the issue. Now more than ever we are seeing computer programming, algorithms etc and they are everywhere in our daily lives. With 
these systems in place, if they are being built on this gap, the gap will stay there, or worse, continue to grow.

"The new context makes the need to close the gender data gap ever more urgent. Artificial intelligence that helps doctors with diagnoses, that scans through CVs, even that conducts interviews with potential job applicants, is already common. But AIs have been trained on data sets that are ridiculed with data gaps - and because algorithms are often protected as proprietary software, we can't even examine whether these gaps have been taken into account."

The book is written for change-makers. To give examples and statistics to back up the need to get women in the room, to evaluate any existing policies (whether in a company, an organisation, council, government, healthcare....) to see if they really are 'gender neutral' or in fact designed for 'the default male'.

Criado-Perez calls her early drafts "vomit drafts" as the book quite literally exploded out of her and she had to immediately get it on paper. After meticulous editing, fact-checking and help from friends and colleagues, the result is a book that is thoroughly well-researched and brimming with examples of what needs to change, and hopeful tellings of when things have changed.

At times the book made me laugh as Criado-Perez details the reaction when a professor at Georgetown University named her literature course "White Male Writers" but no-one blinks an eye when 'Women's Literature' is its own topic. Again, we are made aware of the man as the default. However, it's not all doom and gloom. Criado-Perez shares stories of success, of when the data gap is recognised, systems put in place to correct, and the result. For example, blind auditions for orchestras (traditionally male) have increased the percentage of women taking up roles. We've seen success across the globe, including this report showing how fair algorithms are creating citizens' assemblies - a fair and representative match of the community.

"As the recommendations made by citizens' assemblies increasingly affect public decision-making, the urgency that selection algorithms distribute this power fairly across constituents also grows."

Although this book has a global perspective, for me in Aotearoa, New Zealand, I was drawn to it after a recent survey. The Digital Skills Aotearoa Report, prepared by NZTech, was published in 2020, and included statistics of under-representation of women in a number of industries but primarily tech, science and engineering. Reading Invisible Women gave insight into just why this might be. And that it's not just one big coincidence.

The book will hopefully have a ripple effect. Women I know that have read the book feel equal parts frustrated and ignited to act. But perhaps more importantly, men need to read this book, not just women.

Criado-Perez says "When we are designing a world that is meant to work for everyone we need women in the room". So I urge you, if you are in any sort of capacity for decision making - look around that room. Get women in that room. This book is a call for change, a rallying cry and I thoroughly enjoyed it and recommend it to both women and men. Criado-Perez dedicated the book to "the women who persist: keep on being bloody difficult". Her second book, 'Do It Like a Woman... and change the world' has already received praise and is next on my list to read. Less jaw-dropping and fist-clenching, more inspiring and empowering for young women across the world. 
Flanigan, B., Gölz, P., Gupta, A. et al. Fair algorithms for selecting citizens' assemblies. Nature (2021). https://doi.org/10.1038/s41586-021-03788-6

The opinions expressed are those of the paper author(s) and not He Rourou or The Mind Lab.

He Rourou by The Mind Lab is licensed under a Creative Commons Attribution-NonCommercial-ShareAlike 4.0 International License, except where otherwise noted. [ISSN 2744-7421]

\section{About the Author}

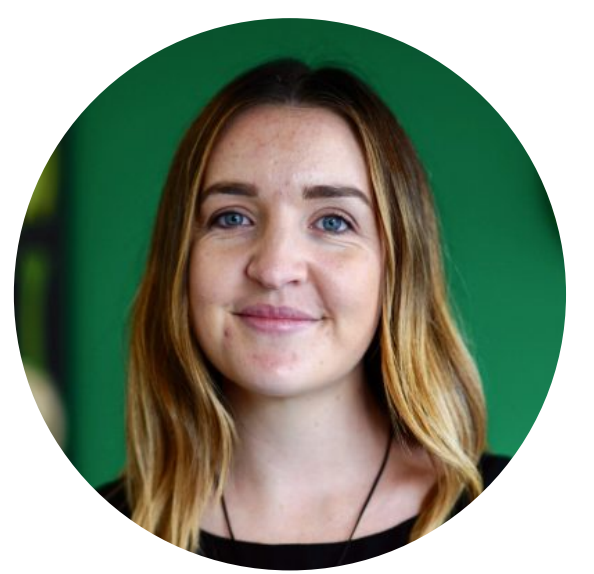

Bex Taylor

https://www.linkedin.com/in/bex-taylor-nz/

Bex Taylor is an optimistic organiser and connector with a 'get stuff done' approach. Part of the marketing team for The Mind Lab, Bex is passionate about raising awareness of the education programmes on offer and transforming people's lives through education and community. An avid traveller, she lived in 5 countries before the age of 30 and has her sights set on more Great Walks of Aotearoa. You can contact Bex at bex.taylor@themindlab.com or find her on LinkedIn. 